JOURNAL OF ASTHMA

Vol. 41, No. 8, pp. 855-861, 2004

ORIGINAL ARTICLE

\title{
The Development and Establishment of a Care Map in Children with Asthma in Taiwan
}

\author{
Sue-Hsien Chen, M.S.N., R.N., ${ }^{1}$ Kuo-Wei Yeh, M.D., ${ }^{2}$ \\ Sue-Huei Chen, Ph.D., ${ }^{3}$ Dah-Chin Yen, M.D., ${ }^{2}$ \\ Teresa J. C. Yin, R.N., Ph.D., ${ }^{4}$ and Jing-Long Huang, M.D.,* \\ ${ }^{1}$ Department of Nursing, Chang Gung Memorial Hospital, and Chang Gung Institute \\ of Technology, Taoyuan, Taiwan \\ ${ }^{2}$ Division of Allergy, Asthma, and Rheumatology, Department of Pediatrics, Chang \\ Gung Children's Hospital and Chang Gung University, Taoyuan, Taiwan \\ ${ }^{3}$ Department of Psychology, National Taiwan University, Taipei, Taiwan \\ ${ }^{4}$ Department of Nursing, Taipei Veterans General Hospital and \\ National Yang-Ming University, Taipei, Taiwan
}

\begin{abstract}
Background. It is often difficult to predict the timing and frequency of asthma attacks. In addition to interrupting the daily life of both the affected child and his/her family, asthma can also pose sudden danger to a child. Based on clinical observations, many asthma-affected children and their parents must constantly adjust themselves to the uncertainty of the disease, which leads to increased stress on the family. The use of care maps has demonstrated increased efficiency and effectiveness in the care of asthma patients from a variety of settings. Objective. We designed this study to construct and evaluate a care map for asthmatic children in Taiwan. Specific attention was placed on comparing the study and control subjects by parental knowledge of asthma, medication used for asthma, hospital readmission, and health care resource usage. Subjects and Methods. The care map was constructed by in-depth interviews with eight sets of parents of children with asthma. Forty-four parents of 42 asthma children were randomized into two groups in the Allergic Clinic of the Chang Gung Children's Hospital. The experimental group of 22 parents received individual instruction and training sessions in addition to the regular care provided to the control group of 22 parents. Results. Forty-two children with asthma were surveyed in this study. To examine the reliability and validity of a care map for children with asthma, a quantitative survey was conducted with 42 outpatient parents with asthmatic children.
\end{abstract}

*Correspondence: Dr. Jing-Long Huang, M.D., Department of Pediatrics, Chang Gung Children's Hospital, 5, Fu-Hsien St., Kweishan, Taoyuan, Taiwan; Fax: 886-3-3274843; E-mail: long@adm.cgmh.org.tw. 
There was less emergency room attending rate in experimental group (6/month; $\mathrm{p}<0.05)$ The understanding of the disease was much improved in parents of experimental group $(13.85 \pm 1.04$ vs. $10.91 \pm 2.14$; $\mathrm{p}<0.01)$. Furthermore, parents acquired a more positive attitude to asthma, and almost all of the control group had irregular follow-ups by a physician and had irregular use of medication. Conclusion. This study emphasizes that a care map in children with asthma (CACM) can be used to educate parents in how to provide the best treatment plan for their children. This study also shows how a CACM can help parents train their children in the best behaviors during asthma attacks. Empathetic assessment and elimination of cultural barriers, a well-designed educational program, and a mutually developed treatment plan could significantly improve the quality of life for families and specific asthma outcomes.

Key Words: Asthma; Asthma care; Care map; Education.

\section{INTRODUCTION}

Asthma is one of the most common chronic diseases worldwide. The trend of morbidity and mortality for children with asthma has gradually increased worldwide over the last 20 years, becoming a grave concern for health providers (1). An increased prevalence and severity of childhood asthma has also been noted in Taiwan (2). Asthma is the most prevalent chronic childhood condition and can have a significant impact on children, also presenting challenges for their families $(3,4)$. As a result of the relative uncertainty and frequency of attacks, asthma can pose sudden danger to children, also interrupting the daily life of both the affected child and his/her family. Although the specific effects of asthma vary dramatically within specific individuals and families, it has been found that many children worry about death and the side effects of medication, in addition to the doubts they have concerning their physical ability (5). Therefore, family care is defined as the strategies enacted by parents to deal with a child's emerging health needs while promoting his or her healthy development $(6,7)$.

Care map of asthma is an effective method for family care. It has been shown to improve asthma care efficiency and effectiveness in variety of care settings (8). The health team has the opportunity to assist families in effectively managing the chronic condition of their children. An important component in care is understanding the family's perception of their situation and existing needs, concerns, and coping strategies (6-9). The case manager must have a consistent, comprehensive, and systematic approach in assessing and intervening with families to be more effective in helping families manage their child's condition. Education in asthma selfmanagement should be tailored to the needs of individual patients with sensitivity to cultural beliefs and practices. Cultural beliefs and language differences may affect the individual's understanding and adherence to the treatment plan (8). However, the process of developing an effective asthma care map for children remains a great challenge for health care executives and case managers to adopt in their institutions. A care map can also be used by interdisciplinary team members as a practical guide in developing a specific case management plan. Therefore, the aim of the study is to describe what it means to develop and evaluate a care map for children with asthma in Taiwan.

\section{SUBJECTS AND METHODS}

\section{Subjects}

The study group was composed of parents of 42 asthmatic children who were followed in the Allergic Clinic of Chang Gung Children's Hospital. The children were chosen at random to serve as the target population of the study. The mean age of the parents was $36.95 \pm 4.61$ years $(84 \%$ were females and $16 \%$ were males). They were all residents of Taipei County. The mean age of their asthmatic children was $5.54 \pm 3.04$ years (mode, 5 years); the children had been diagnosed with asthma at least a half year previously. All subjects were persistent asthmatic patients, the severity of which was graded according to Global Initiative for Asthma (GINA) guideline (10).

\section{Study Design and Procedures}

\section{Phase I: Development of a Care Map for} Children with Asthma

A care map for children with asthma (CACM) is best developed through an interdisciplinary team that includes physicians from the divisions of pediatric allergy, case management, nursing administration, respiratory therapists, staff nurses, and a pulmonary case manager, usually a steering committee charged with implementing case management systems. A review of 
the literature and current national guidelines from the National Heart Lung and Blood Institute (NHLBI) on asthma management was performed (10). Initially, the nine items of CACM were constructed by in-depth interviews with eight parents of children with asthma. A CACM program includes recognition of asthma signs and symptoms, daily medication instructions, the interpretation of peak flow meter rates, management of exercise-induced asthma, diet, the importance of followup, health care resources, and separate emergency action plans for asthma and allergy episodes. Then, the validity of the care content was further evaluated by a panel of established experts. Data collection regarding the critical elements and the attached time frames of delivery of patient care activities are essential in the development of CACM. Team members meet numerous times to discuss and develop the care map for children with asthma. The institutional data provided evidence that varied approaches to the management of asthma are necessary. Training and education regarding a CACM for all health care providers involved in the particular specialty or diagnosis should be completed before implementation of the plan. Goals of standardizing practice within the current NHLBI recommendations, enhancing the quality and improving outcomes for this population, were identified. A CACM is a kind of algorithm outlining assessments and related treatment. It was based on patient response to the specified interventions for each of the categories of "mild," "moderate," and "severe", asthma. Measures of outcome included quality, feasibility of use, any delays or variations in care, participant knowledge relating to asthma and correct inhaler technique, readmission (to the emergency room, and hospitalizations), and compliance.

Phase II: Evaluation of a Care Map for Children with Asthma

Subjects who satisfied the inclusion criteria were randomized into the control group of 22 parents or the experimental group of 20 parents. The control group received usual care for asthma management, which included administration of bronchodilator drugs (orally or by inhalers), prophylactic anti-inflammatory drugs (inhaled steroids), and preventive care. The experimental group received a copy of a CACM in addition to the usual care. The intervention included individual instruction and training sessions during the first month following the baseline interview. The principal investigator was a pediatric nurse practitioner with 19 years of experience in the asthma department of the children's hospital. She took the initiative in educating parents in recurring respiratory symptoms and asthma. She focuses on teaching parents to recognize, document, and describe asthma symptom patterns and discusses tools that have been shown to improve the care of children with asthma (and other illnesses). Consent was first obtained from the authorities at the study-involved hospital prior to any study process or method being conducted. An explanation of the study details was provided to all study participants, and their parents were requested to sign a consent form. The control group and intervention groups were followed for 3 months. Data on the health status were collected by using a diary and a chart record for follow-up data. Data on other outcome variables were collected in the questionnaire.

The questionnaire design was based on a modification of a preexisting design (11) and contained basic family information and an asthma knowledge scale. The basic family information surveyed included the previous history of asthma attacks and associated treatment, parental smoking history, medication use for asthma, hospital readmission, health care resource use, and related asthmatic information. The asthma knowledge scale consisted of a series of 20 questions surveying the child's knowledge regarding asthma, with a profile such that the higher the scale value, the greater the knowledge regarding asthma. The asthma attitude scale included 25 questions, with a profile such that the higher the scale value, the greater the positive attitude regarding asthma.

\section{Statistical Analysis}

All data obtained was imported into, checked by, and analyzed by using the Statistical Package for Social Sciences (SPSS), Version 10.0 for Windows. Descriptive statistics were obtained for demographic variables, asthma severity, and types of asthma medication used. For the analysis of the relationship between the demographic variables and inhalation skill, we used an independent sample Student's $t$-test and one-way ANOVA. Pearson product moment correlations coefficients were used to evaluate the relationship between the frequency of asthma attack, age of sufferer at the time of asthma onset, and participant knowledge and attitude regarding asthma (12).

\section{RESULTS}

\section{Demographic Features for Parents and Asthmatic Children}

Forty-two parents of asthmatic children (22 control and 20 intervention parents) completed the 3-month study. Table 1 shows the demographic characteristics 
Table 1. Demographic characteristics of parents of children with asthma.

\begin{tabular}{|c|c|c|c|}
\hline Variables & $\begin{array}{l}\text { Control } \\
(n=22)\end{array}$ & $\begin{array}{l}\text { Experimental } \\
\quad(n=20)\end{array}$ & $\begin{array}{l}\chi^{2} \text { values } \\
\text { ( } \mathrm{p} \text { values })\end{array}$ \\
\hline Gender $(\%)$ & & & 0.63 \\
\hline Male & 13.6 & 10 & \\
\hline Female & 86.4 & 90 & \\
\hline Age distribution $(\%)$ & & & 0.53 \\
\hline $21-30$ years old & 4.5 & 10 & \\
\hline $31-40$ years old & 81.1 & 65 & \\
\hline $41-50$ years old & 13.6 & 25 & \\
\hline Education level (\%) & & & 0.72 \\
\hline Junior high school & 27.3 & 25 & \\
\hline Senior high school & 50.0 & 45 & \\
\hline College or university & 22.7 & 25 & \\
\hline Master and beyond & 0 & 5 & \\
\hline
\end{tabular}

*Significant difference $(\mathrm{p}<0.05)$ from instrument; values are expressed as the mean.

pertaining to study participants' basic information. The two groups of participants were similar in terms of age and educational distribution, indicating that the study did not differ significantly between the groups. Table 2 provides basic information on the asthmatic children at baseline. Health status and use measures during the study did not differ significantly between the groups. The average age of asthma onset was $3.58 \pm 2.5$ years. The asthmatic condition was rated "severe" in $38.1 \%$ of the children and "moderately severe" or "mild" in $61.9 \%$ of the children. Thirty-seven $(88.1 \%)$ children suffered from at least one acute asthmatic attack within the preceding 3 months, with 4 (9.5\%) having suffered more than four attacks during the preceding 3 months. Almost all the asthmatic children had irregular follow-ups by a physician and irregular use of inhaler medication. Distribution of the parents' responses to markers of asthma management are shown in Table 3.

\section{Medication Use for Asthma}

Almost three quarters of the sample (69.0\%) were prescribed daily use of inhaled $\beta$-agonist for asthma

Table 2. Demographic characteristics of asthmatic children.

\begin{tabular}{|c|c|c|c|}
\hline Variables & $\begin{array}{l}\text { Control } \\
(n=22)\end{array}$ & $\begin{array}{l}\text { Experimental } \\
\quad(n=20)\end{array}$ & $\begin{array}{l}\chi^{2} \text { values } \\
(\mathrm{p} \text { values })\end{array}$ \\
\hline Gender $(\%)$ & & & 0.93 \\
\hline Male & 63.6 & 65 & \\
\hline Female & 36.4 & 35 & \\
\hline Age distribution & & & 0.34 \\
\hline$<3$ years old & 18.2 & 10 & \\
\hline $3-6$ years old & 45.4 & 50 & \\
\hline $7-9$ years old & 18.2 & 20 & \\
\hline$>9$ years old & 18.2 & 20 & \\
\hline Received Chinese herb therapy & & & 0.72 \\
\hline Yes & 54.5 & 60 & \\
\hline No & 45.5 & 40 & \\
\hline $\begin{array}{l}\text { Hospital admissions in } \\
\text { preceding } 3 \text { months }\end{array}$ & & & 0.56 \\
\hline Yes & 9.1 & 15 & \\
\hline No & 90.1 & 85 & \\
\hline
\end{tabular}

*Significant difference $(\mathrm{p}<0.05)$ from instrument; values are expressed as the mean. 
Table 3. Distribution of asthma management.

\begin{tabular}{llr}
\hline Markers of parental asthma management & \multicolumn{1}{c}{ Frequency } & Percentage \\
\hline Follow-up by physician in past 3 months & Compliance & 31.8 \\
& Poor compliance & 68.2 \\
Hospital admissions in preceding 3 months & No admissions & 93.1 \\
& 1 admission & 9.5 \\
& 2 admissions & 2.4 \\
Visits to the emergency room in preceding 3 months & None admissions & 54.6 \\
Visits to the emergency room after 3 months & $\geqq 1$ visit & 45.4 \\
& None & 61.9 \\
Reasons of irregular use of medication & $\geqq 1$ visit & 38.1 \\
& Clinical improvement & 42.4 \\
& Being symptom-free & 35.8 \\
\end{tabular}

management, whereas $45.2 \%$ were prescribed oral Montelukast as their daily asthma medication. Almost all of the experimental group (85\%) used a peak flow meter and were taking inhaled medications on a regular basis. Their use of inhaled $\beta_{2}$-agonist was significantly lower $(0.60 \pm 0.03)$ than in control group $(1.32 \pm 0.41)$ $(\mathrm{p}<0.05)$. The control group had to supplement their daily doses with extra puffs from the $\beta$-agonist inhaler. In addition, $13(31.0 \%)$ children required a course of oral corticosteroids in the control group.

\section{Health Care Resource Use}

Table 4 presents a summary of differences in asthma-related health services events when the intervention period was compared with the preceding period for each group. The experimental group had a usage rate of the emergency room (ER) less than that of the control group $(\mathrm{p}<0.05)$. Five subjects $(11.9 \%)$ had hospital admissions for asthma in the preceding 3 months. There were no significant differences in the number of hospital admissions. In the control group, the subjects had not spoken on the telephone with either a physician or a nurse about asthma-related problems, and almost all of them had irregular follow-up sessions with a physician and irregular use of medication.

\section{Parent's Knowledge of Asthma and Attitude}

The results of the present study demonstrated a significant difference in the knowledge of parents in the two groups. The parents who participated in the care map program demonstrated significantly higher knowledge. The results are summarized in Table 5 . The posttest scoring for the knowledge of parents was significantly higher in experimental group $(13.85 \pm 1.04$ vs. $10.91 \pm 2.14 ; \mathrm{p}<0.01)$. Furthermore, parents acquired a more positive attitude toward asthma (Table 5). Their attitude became more positive toward giving asthma medication to prevent and/or to deal with the attacks of asthma more appropriately. The study found no correlation between the knowledge or the attitude, and the socioeconomic level.

Table 4. The rate of emergency room visits in the two groups $(\mathrm{N}=42)$.

\begin{tabular}{lcccc}
\hline Parameter & $\mathrm{n}$ & Mean (SD) & $t$ values & p values \\
\hline Control group & 22 & $0.59(0.50)$ & 3.2 & $0.003^{*}$ \\
Experimental group & 20 & $0.15(0.37)$ & & \\
\hline
\end{tabular}

*Significant difference $(\mathrm{p}<0.05)$ from instrument; values are expressed as the mean. 
Table 5. Knowledge and attitude scoring of parent's in the two groups $(\mathrm{N}=42)$.

\begin{tabular}{|c|c|c|c|c|}
\hline Parameter & $n$ & Mean (SD) & $t$ values & $\mathrm{p}$ values \\
\hline \multicolumn{5}{|l|}{ Knowledge } \\
\hline \multicolumn{5}{|l|}{ Pretest } \\
\hline Control group & 22 & $9.05(3.54)$ & 4.81 & 0.63 \\
\hline Experimental group & 20 & $8.60(2.26)$ & & \\
\hline \multicolumn{5}{|l|}{ Posttest } \\
\hline Control group & 22 & $10.91(2.14)$ & 5.75 & $0.00 *$ \\
\hline Experimental group & 20 & $13.85(1.04)$ & & \\
\hline \multicolumn{5}{|l|}{ Attitude } \\
\hline \multicolumn{5}{|l|}{ Pretest } \\
\hline Control group & 22 & $86.3(7.36)$ & 0.78 & 0.94 \\
\hline Experimental group & 20 & $86.5(7.47)$ & & \\
\hline \multicolumn{5}{|l|}{ Posttest } \\
\hline Control group & 22 & 86.7 (6.82) & 0.41 & 1.72 \\
\hline Experimental group & 20 & $88.5(6.49)$ & & \\
\hline
\end{tabular}

*Significant difference $(\mathrm{p}<0.05)$.

\section{DISCUSSION}

The study findings support both hypotheses tested: a CACM with current guidelines for asthma care, coupled with health team support for change in practice behavior, would increase the number of children receiving appropriate use of medication. A CACM in practice provided a method for influencing the frequency and intensity of children's asthma symptoms and parental attitudes toward their children's illness. They tended to have regular use of preventive medication and more regular visits to the physician. In particular, knowledge improvement included measures that can be taken to prevent an attack, understanding about what causes an attack, and estimation of the severity of an attack. Therefore, a CACM was developed specifically to help their individual child know what to do in the event of an asthma attack.

This study demonstrated that a CACM can provide tailored education for individual families and individual children about the best treatment plan. Such tailored interventions may include support, time for listening to needs, and the provision of continuous and accurate information about the present situation and expectations $(11,13-15)$. It is also important for the nurse to provide additional emotional support. Some studies reported that parents who received instruction about asthma were more confident in treating asthma episodes at home $(11,13)$. The National Asthma Education and Prevention Program (NAEPP) suggests that the most effective educational program is one that is tailored to the needs of the child and his or her family (10). After assessing the child and family's knowledge about the disease and treatment, the nurse should make an initial educational plan. It is also important to reinforce key teaching points at the end of each visit.

Our study also revealed that cultural influences can have a significant impact on adherence, because they affect how families perceive asthma. According to the NAEPP, traditional Hispanic medicine often refers to asthma as "cold." In this culture, remedies are considered safer if they are the opposite of the illness, an asthma treatment plan that includes a hot beverage might be more likely to be accepted $(16,17)$. The study has found that in cultures that value an external locus of control (belief that destiny controls their lives), little value is placed on preventive medications. This is a significant challenge for the nurse who works with families with asthmatic children.

\section{ACKNOWLEDGMENTS}

We thank the study participants/parents of the Chang Gung Children's Hospital in this study for their help. We also thank Dr. Wu Max for his efforts in assisting in the writing and revision of this manuscript.

\section{REFERENCES}

1. Mendenhall AB, Tsien AY. Evaluation of physician and patient compliance with the use of peak flow meters in commercial insurance and Oregon health plan asthmatic populations. Ann Allergy, Asthma, Immun 2000; 84(5):523-527. 
2. Kao CC, See LC, Yan DC, Ou LS, Huang JL. Time trends and seasonal variations in hospital admissions for childhood asthma in Taiwan from 1990 to 1998. Asian Pac J Allergy Immunol 2001; 19(2):63-68.

3. Kurnat LE, Moore MC. The impact of a chronic condition on the families of children with asthma. J Pediatr Nurs 1999; 25(4):288-293.

4. Dalheim-Englund A-C, Rydström I, Norberg A. Being the parent of a child with asthma. J Pediatr Nurs 2001; 27(4):288-293.

5. Brook U, Mendelberg A, Heim MG. Increasing parental knowledge of asthma decreases the hospitalization of the child: a pilot study. J Asthma 1993; 30(1):45-49.

6. Horner S. Catching the asthma: family care for school-aged children with asthma. J Pediatr Nurs 1998; 13(4):356-366.

7. Boccuti L, Celano M, Geller R, Phillips KM. Development of a scale to measure children's metered-dose inhaler and spacer technique. Ann Allergy, Asthma, Immun 1996; 77(3):217-221.

8. Pachter LM, Cloutier MM, Bernstein BA. Ethnomedical (folk) remedies for childhood asthma in a mainland Puerto Rican community. Arch Pediatr Adolesc Med 1995; 149(9):982-988.

9. Cohen R, Franco K, Motlow F, Reznik M, Ozuah PO. Perceptions and attitudes of adolescents with asthma. J Asthma 2003; 40(2):207-211.
10. National Asthma Education and Prevention Program. The Expert Panel Report II: Guidelines for the Diagnosis and Management of Asthma (EPRII). Washington, DC: U.S. Department of Health and Human Services, 1997:97-4051.

11. Chen SH, Teresa JC, Huang JL. Exploring of the skills for inhalation therapy in schoolchildren with asthma in Taiwan. Ann Allergy, Asthma, Immun 2002; 89(3):311-314.

12. Johnson R, Kuby P. Elementary Statistics. 8th ed. Pacific Grove, CA: Duxbury, 2000:147.

13. Lawrence G. Asthma self-management programs can reduce the need for hospital-based asthma care. Respir Care 1995; 40(1):39-43.

14. Myers TR, Chatburn RL, Kercsmar CM. A pediatric asthma unit staffed by respiratory therapists demonstrates positive clinical and financial outcomes. Respir Care 1998; 43(1):22-29.

15. Lozano P, Fishman P, Vonkoff M, Hecht J. Health care utilization and cost among children with asthma who were enrolled in a health maintenance organization. Pediatrics 1997; 99(6):757-764.

16. Divertie V. Strategies to promote medication adherence in children with asthma. MCN 2002; 27(1):10-18.

17. Celano M, Geller JR, Phillips MK, Ziman R. Treatment adherence among low-income children with asthma. J Pediatr Psychol 1998; 23(6):345349 . 